\title{
Application of basic drying theory to determine drying mass constants of selected seafoods
}

\author{
Orua Okon Antia ${ }^{1,}{ }^{*}$, William Adebisi Olosunde ${ }^{1}$ and Emem Orua Antia ${ }^{2}$ \\ ${ }^{1}$ Department of Agricultural and Food Engineering, University of Uyo, Nigeria. \\ 2 Department of Chemical and Petroleum Engineering, University of Uyo, Nigeria.
}

Global Journal of Engineering and Technology Advances, 2021, 07(01), 137-143

Publication history: Received on 14 March 2021; revised on 18 April 2021; accepted on 21 April 2021

Article DOI: https://doi.org/10.30574/gjeta.2021.7.1.0062

\begin{abstract}
The drying of seafood could ensure increase in life span, minimization of storage space, ease of transportation, etc of the product. It is therefore, necessary to dry and know when to stop drying at an appropriate moisture content that would minimize associated challenges in promoting food security. In this study, selected sea foods, such as prawn and oyster were obtained and then dried to determine their drying mass constants using model equation developed based on basic drying principle. The value of the constants obtained would provide data bank to facilitates prediction of mass of the drying material at given time that would correspond to any desired moisture content, provided the initial moisture content of the material is known. The plots of moisture content against drying time, drying rate against drying time and moisture content versus $\left[\mathrm{M}_{\mathrm{o}}\right] /\left[\mathrm{M}_{\mathrm{t}}\right]$ were carried out. It was observed that increase in size of the drying material increased the drying time. Moreover, the drying rate curve resembles a typical drying curve. Hence, the experimental values obtained are reliable. Technical analysis showed that the drying mass constants for prawn and oyster are $0.2950 \pm$ 0.0119 and $0.2453 \pm 0.0476$, respectively.
\end{abstract}

Keywords: Drying mass constant; Moisture content; Model equation; Seafood.

\section{Introduction}

The essence of drying food materials is to remove moisture to increase its life span, and promotes food security. The materials when dried would become lighter and smaller; and would encourage ease of transporting them for commercial purpose. In addition to these advantages, the drying of sea food would minimize storage space and packaging challenges; keep the material to be unique, nutritious and tasty. Some major sea foods of economic importance include prawn, fish and oysters. In Nigeria, prawn is locally known as 'abu ekem' in Ibibio, 'oporo' in Igbo and 'ede' in Yoruba [1, 2, 3, 4, 5]. In Nigeria, oyster is locally known as 'nkop' in Ibibio and 'gigei' in Yoruba. It contains high quality protein and has short shelf life and favourable flavour [2, 6, 7]. Since seafoods are highly perishable, it is necessary to preserve and handle them through effective equipment and techniques such as bed drying, drum drying, micro wave- vacuum drying, freeze drying, convective drying, spray drying, combined thermal hybrid drying, shelf drying, sun drying, infrared radiation drying, oven drying and commercial food dehydration. The application of each technique and equipment may have its own disadvantages. The drying temperature that was found to be favourable for shrimp was 700C $[8,9]$. This temperature could be used in drying other seafoods. However, oven drying method could be widely accepted because it is cost effective and can accommodate large volume of samples at the same time; and so would produce higher throughout, high accurate and precise result. The moisture content of a material subjected to drying could be calculated based on data obtained from experimental runs.

\footnotetext{
${ }^{*}$ Corresponding author Orua Okon Antia

Department of Agricultural and Food Engineering, University of Uyo, Nigeria.

Copyright $(2021$ Author(s) retain the copyright of this article. This article is published under the terms of the Creative Commons Attribution Liscense 4.0.
} 
Generally, moisture content (MC) wet basis $(\mathrm{wb})=\frac{\text { (Initial mass }- \text { Final mass) }}{\text { Inital mass }}$

$$
\mathrm{MC}(\mathrm{wb})=\frac{\left(\mathrm{M}_{\mathrm{t}}-\mathrm{M}_{\mathrm{d}}\right)}{\mathrm{M}_{\mathrm{t}}} \times 100 \%
$$

Where, $M_{t}$ is the mass of the sample at a given of the time, t during drying, $M_{d}$ is dry bone mass of sample.

$$
\begin{aligned}
\text { Moisture content }(\mathrm{MC}) \text { dry basis }(\mathrm{db}) & =\frac{(\text { Initial mass }- \text { Final mass })}{\text { Final mass }} \\
\operatorname{MC}(\mathrm{db}) & =\frac{\left(\mathrm{M}_{\mathrm{t}}-\mathrm{M}_{\mathrm{d}}\right)}{\mathrm{M}_{\mathrm{d}}} \times 100 \%
\end{aligned}
$$

Antia et al. $[10,11]$ developed a model based on Equation 1.2 by expressing $\mathrm{M}_{\mathrm{d}}$ as:

$$
\mathrm{M}_{\mathrm{d}}=\mathrm{FM}_{\mathrm{o}}
$$

Where, $F$ is the fraction of percentage of initial mass $\left(M_{o}\right)$ of freshly harvested sample that gives bone dry mass $M_{d}$ which is the mass where no more change in mass of the sample occur during drying.

From Equation 1.5, Equation 1.4 can be expressed as:

$$
\mathrm{MC}(\mathrm{wb})=\left\{1-\mathrm{F} \frac{\left[\mathrm{M}_{0}\right]}{\left[\mathrm{M}_{\mathrm{t}}\right]}\right\} \times 100 \%
$$

From Equation 1.5, a model could be written based on Equation 1.4 as:

$$
\mathrm{MC}(\mathrm{db})=\left\{\frac{1}{\mathrm{~F}\left(\frac{\mathrm{M}_{0}}{\mathrm{M}_{\mathrm{t}}}\right)}-1\right\} \times 100 \%
$$

Based on the model Equation 1.6 and 1.7, the F value could be referred to as drying mass constant. In this study, the drying mass constants of some seafoods were determined in order to provide a data bank that could be used with empirical Equation 1.6 and 1.7 developed from the basic drying principle to predict easily at a given time the mass of the drying material that would correspond to any desired moisture content, once the initial mass is known.

\section{Material and methods}

\subsection{Materials and Equipment}

The materials and equipment that were used are oven, weighing balance, prawn and oyster.

\subsection{Sourcing of Materials}

The fresh samples of sea food were sourced from a local beach market in Itu, Akwa Ibom State, Nigeria.

\subsection{Preparation of Sample}

Prior to drying, the individual samples were cleaned, sorted and grouped into three different sizes namely: large, medium, and small size samples. The samples were dried in a hot air conventional oven.

\subsection{Determination of Moisture Content (MC)}

The selected seafoods were dried at $70^{\circ} \mathrm{C}$. Drying of the samples was done in triplicate. The reduction in weight of the drying samples was monitored at an interval of 1 hour until constant mass was achieved. The digital electronic weighing balance with $0.01 \mathrm{~g}$ precision was employed in measuring the mass of the samples.

\subsection{Experimental Procedure}

The sample moisture content was calculated using Equation 1.2. The experimental data obtained was used in plotting graph of moisture content versus time of drying. A graph of drying rate versus drying time was plotted for all the size ranges per sample; and the bulk sample. The standardized values of $M C$ and $\frac{M_{0}}{M_{t}}$ were calculated for the three size ranges 
and bulk sample [10]. These values of MC were plotted against $\frac{\mathrm{M}_{0}}{\mathrm{M}_{\mathrm{t}}}$ for each of the samples based on the model Equation 1.6. The value of the slope of this graph is the drying mass constant for the selected seafoods dried.

\section{Results and discussion}

\subsection{Determination of Drying Mass Constant of Prawn}

Figures 1 and 2 show moisture content variation against time of drying the various size ranges of prawn $d r i e d$ at $70^{\circ} \mathrm{C}$.

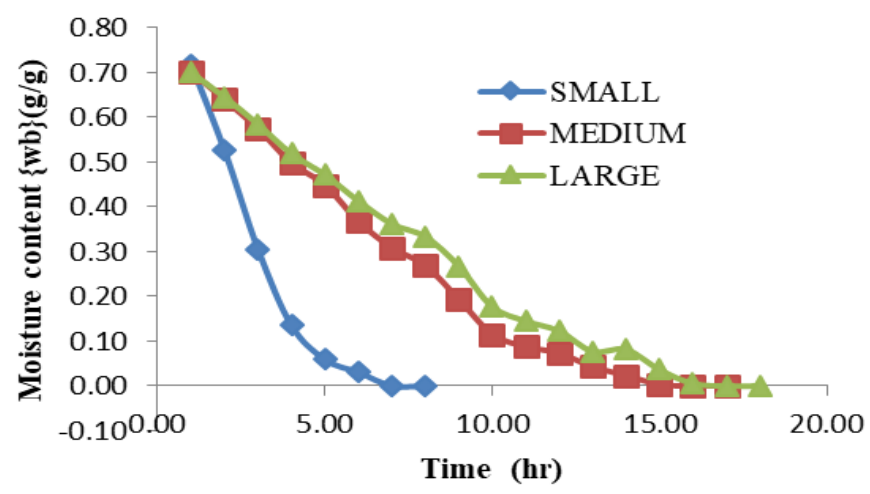

Figure 1 Moisture content variation against time of drying the different size ranges of prawn.

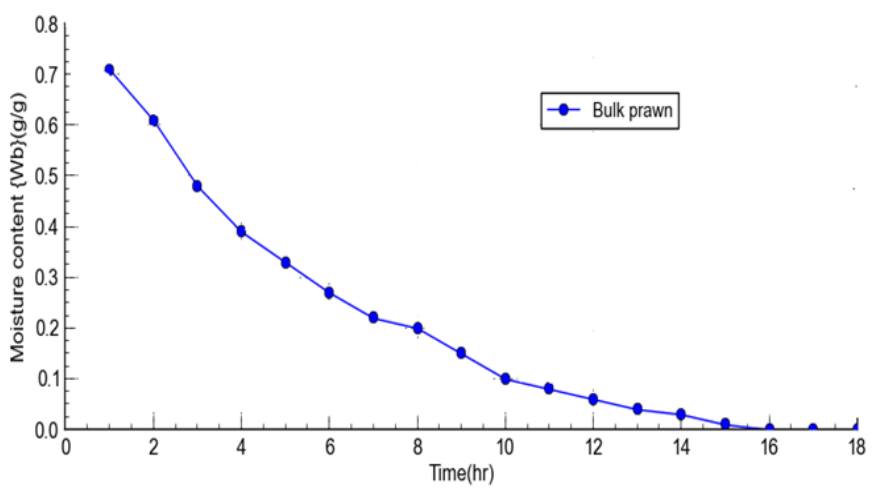

Figure 2 Moisture content variation against time of drying the bulk of prawn

The moisture content of each sample size decreased with increase in drying time. This shows that moisture content is not dependent on the size range of the sample. The drying rate (DR) obtained per drying time for each size is given in Figures 3 and 4

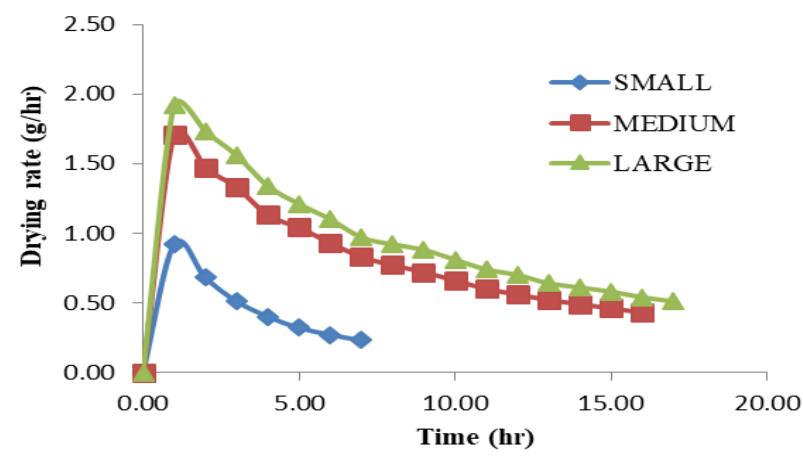

Figure 3 Drying rate against drying time for the different size ranges of prawn 


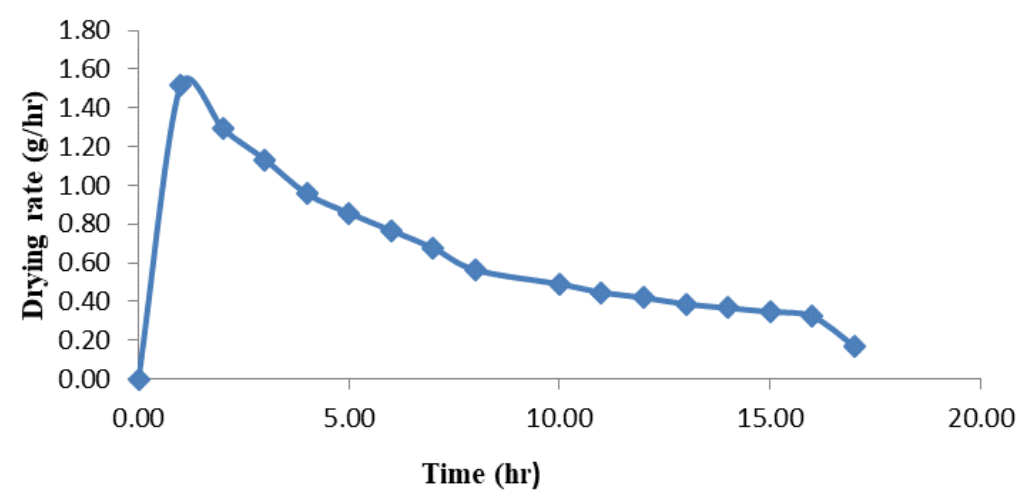

Figure 4 Drying rate against drying time for bulk prawn

The drying curve obtained is similar to an ideal drying curve. This indicates that the experimental data gotten are reasonably valid; and can be used for analysis to obtain empirical relations or predicting moisture content wet basis and dry basis for the fresh sample used in this work as was discussed by [10]. The rate of drying was noted and observed for all the prawn sizes decreased with increase in drying time as shown in Figures 3 and 4. There was an increase in drying rate at the initial drying periods and later decreased with increase in drying period. The $\frac{M_{o}}{M_{t}}$ ratio was computed and standardized based on model Equation 1.6. Plots of standardized values of MC against that of the $\frac{\mathrm{M}_{\mathrm{o}}}{\mathrm{M}_{\mathrm{t}}}$ ratios are as shown in Figures 5 and 6.

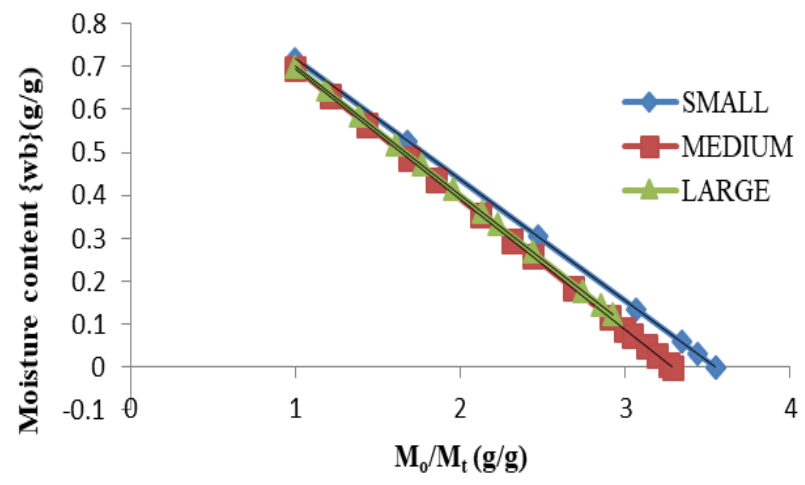

Figure 5 Moisture content against $\frac{\mathbf{M}_{\mathbf{o}}}{\mathbf{M}_{\mathbf{t}}}$ for the different size ranges of prawn

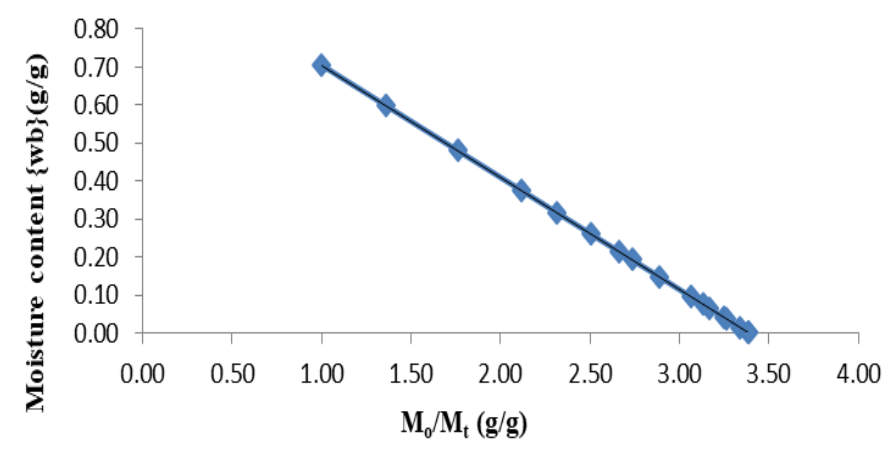

Figure 6 Moisture content against $\frac{M_{0}}{M_{t}}$ for bulk prawn

The drying mass constants of the small, medium, large and bulk quantities of prawn are $0.2819,0.3044,0.3000$, and 0.2950 , respectively. The standard deviation for the sizes from the bulk quantity was obtained as 0.0119 . This suggests 
that the drying mass constant values for the small, medium, large sizes are close to the values of the drying mass constant of the bulk prawn; and the drying mass constant of the bulk can serve as a representative for the other sizes. The graph has a coefficient of determination $\left(\mathrm{R}^{2}\right)$ of 1 which suggests a good quality fit. This may imply that the equation is reliable for moisture content prediction.

\subsection{Determination of Drying Mass Constant of Oyster}

Figures 7 and 8 contain the change in moisture content per drying time for the different size ranges of oyster which was dried at a temperature of $70^{\circ} \mathrm{C}$ till constant mass was achieved.

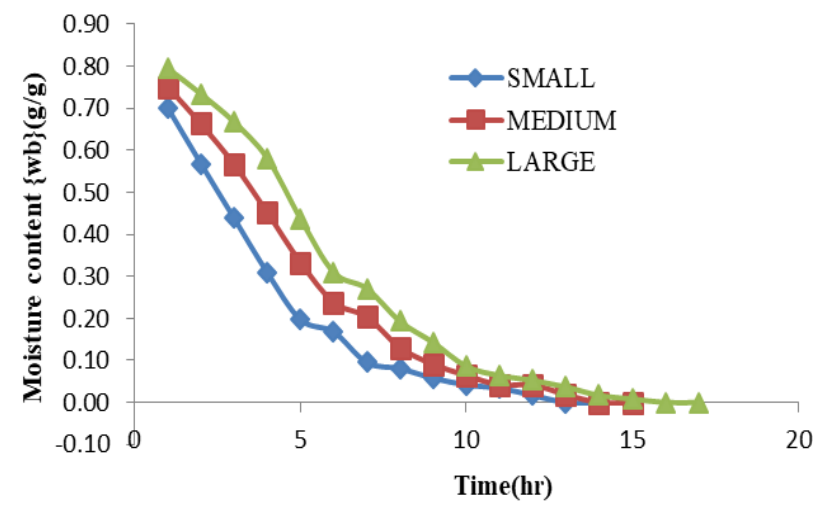

Figure 7 Moisture content variation against time of drying different size ranges of oyster

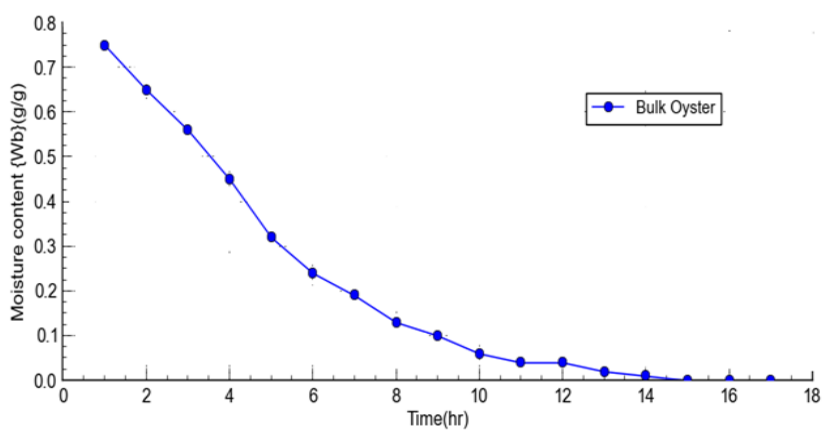

Figure 8 Moisture content variation against time of drying the bulk of oyster

Each sample size moisture content increased as drying period increased. It is seen that the moisture content is independent of sample size. Figures 9 and 10 show the drying rate of the sample sizes and bulk sample, respectively.

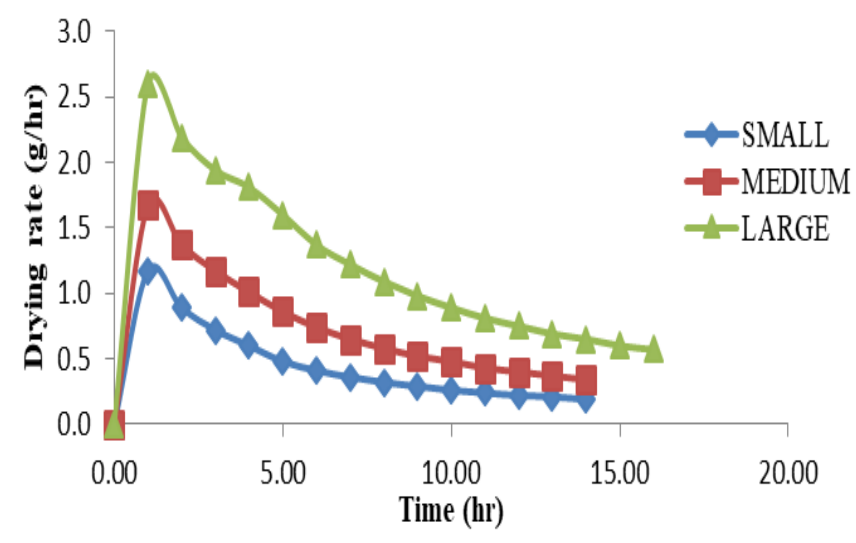

Figure 9 Drying rate against drying time for the different size ranges of oyster 


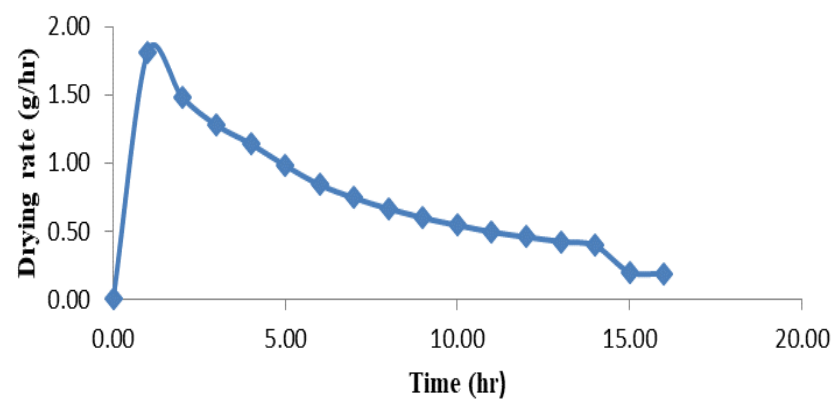

Figure 10 Drying rate against drying time for bulk oyster

The drying curves shown in Figures 9 and 10 resemble an ideal drying curve. The large size had the highest drying rate value while the lowest value was recorded for the small size oyster. The drying rate values for all the oyster sizes decreased with increase in drying time. The drying rates of the oyster sizes increased at initial drying time. The standardized values of $\frac{\mathrm{M}_{\mathrm{o}}}{\mathrm{M}_{\mathrm{t}}}$, and moisture content for the three sizes and the bulk samples were plotted as shown in Figures 11 and 12.

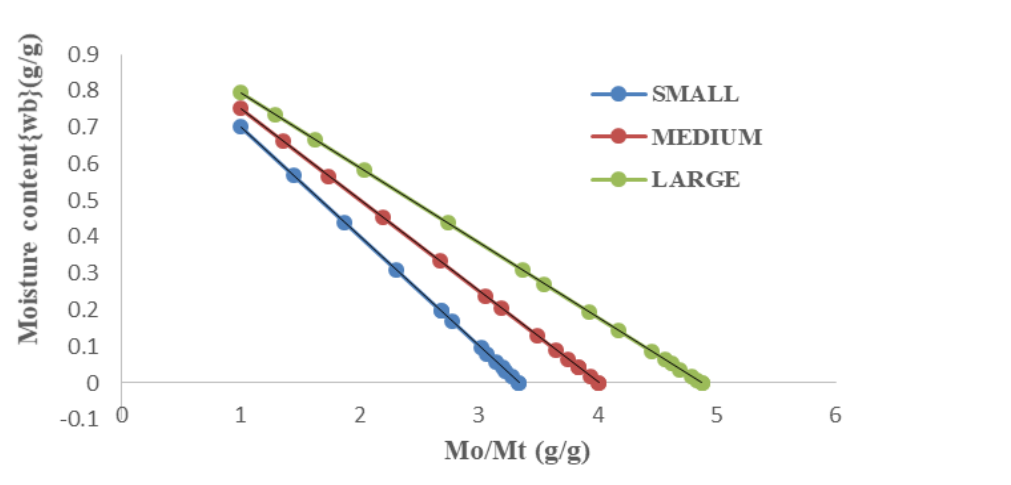

Figure 11 Moisture content against $\frac{\mathbf{M}_{\mathbf{o}}}{\mathbf{M}_{\mathbf{t}}}$ for the different size ranges of oyster

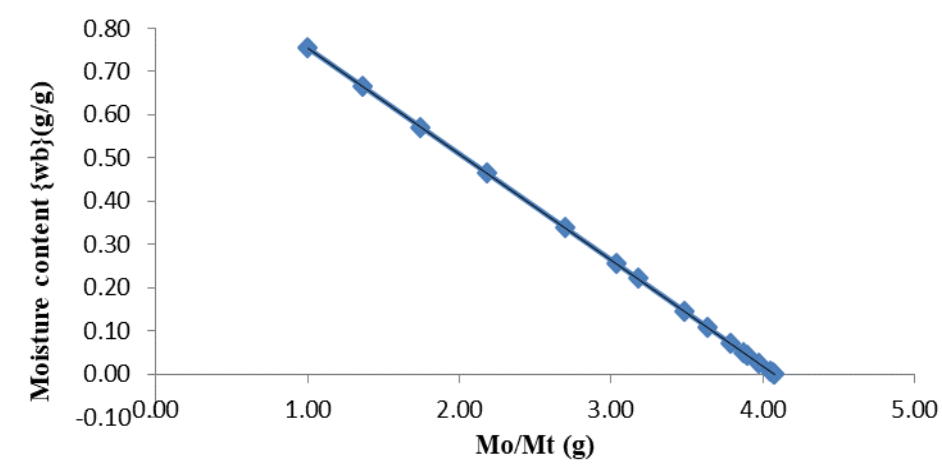

Figure 12 Moisture content against $\frac{\mathbf{M}_{\mathbf{o}}}{\mathbf{M}_{\mathbf{t}}}$ for bulk oyster

The slopes of the graphs which were obtained are equivalent to the drying mass constants of the model Equation 1.6 respectively, as $0.2992,0.2492,0.2051$, and 0.2453 for the small, medium, large and bulk oyster. The drying mass constants had a standard deviation of 0.0544 from the bulk drying mass constant which suggests that the bulk drying mass constant can be used in place of the drying constant of the three sizes. The equation has a coefficient of determination $\left(\mathrm{R}^{2}\right)$ of 1 which suggests a good fit for the data. 


\section{Conclusion}

The drying time of the samples increased with increase in size. The drying mass constant based on model Equation 1.6 were obtained for prawn and oyster; and could be used to forecast their masses at any given time with respect to any desired moisture content during drying.

\section{Compliance with ethical standards}

\section{Acknowledgments}

I acknowledge all authors of articles and books read and used in this work.

\section{Disclosure of conflict of interest}

There is no conflict of interest for this manuscript.

\section{References}

[1] Kaiser MJ, Broad G, Hall SJ. Disturbance of intertidal soft-sediment benthic communities by cockle hand raking. J. Sea Res. 2001; 45: 119-130.

[2] Amadi LO. Mortality and microbial diversity of raw, processed and storage of mangrove oysters (Crassostrea gasar). International Research Journal of Public and Environmental Health. 2016; 3(1): 7-13.

[3] Mortenson PB. This is not a Weasel: A Close Look at Nature's Most Confusing Terms. John Wiley \& Sons. 2010.

[4] Sagar VR, Suresh KP. Recent advances in drying and dehydration of fruits and vegetables: a review. J Food Sci Technol. 2010; 47(1): 15-26.

[5] Boyer R, Huff K. Using Dehydration to Preserve Fruit, Vegetables, and Meats. Virginia Cooperative Extension Publication. 2008; 348-597.

[6] Wikipedia. 2021.

[7] Tidwell JH, Allan GL. "Fish as Food: Aquaculture's Contribution Ecological and Economic Impacts and Contributions of Fish Farming and Capture Fisheries". EMBO Reports. 2001; 2(11): 958-963.

[8] Si X, Chen Q, Bi J, Wu X, Yi J, Zhou L, Li Z. Comparison of different drying methods on thephysical properties, bioactive compounds and antioxidant activity of raspberry powders. J Sci Food Agric. 2016; 96(6): 2055-62.

[9] Tirawanichakul S, Phatthalung WN, Tirawanichakul T. Drying Strategy of Shrimp Using Hot Air Convection and Hybrid Infrared Radiation/Hot Air convection. WalailakJ Sci and Tech. 2008; 5(1): 77-100.

[10] Antia 0, Oboh I, Olosunde W. Determination of Drying Constant of selected Roots and Tuber. International Journal of Trend in Scientific Research and Development. 2019; 3(4): 717-722.

[11] Antia, O 0, Kessington O, Aluyor E, Ebunilo, P. Study of moisture content dynamic of fresh palm nuts during drying. Internatonal Journal of Engineering Science Invention. 2014; 3(2): 19-23. 